\title{
Práticas midiáticas de (i)migrantes latino-americanos pelo mundo: pela promoção de cidadanias e sociabilidades
}

Samira Moratti Frazão

COGO, Denise Maria.

\section{Latino-americanos em diáspora:}

usos de mídias e cidadania

das migrações transnacionais.

Rio de Janeiro: Tríbia, 168p., 2012.

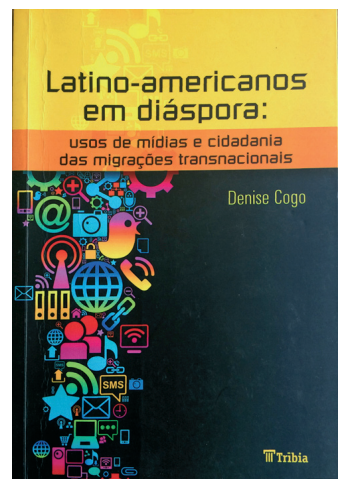

Resumo: O livro é resultado de uma pesquisa promovida entre os anos de 2007 e 2009 por meio do "Grupo de Pesquisa Mídia, Cultura e Cidadania", vinculado ao Programa de Pós-Graduação em Ciências da Comunicação da Unisinos. A proposta foi realizar um mapeamento sobre as práticas de produção midiáticas, feitas por indivíduos ligados ou não a grupos e demais associações de imigrantes latino-americanos, além das organizações que também observam esse fluxo migratório em particular. Tais práticas se referem aos espaços de informação disponíveis na internet, como blogs, sites e demais redes sociais, e por meios impressos como jornais e revistas, locais considerados pela autora como "espaços midiáticos multiterritoriais" (COGO, 2012, p. 15), através dos quais os imigrantes podem estabelecer conexões com suas redes de sociabilidade, bem como promover informações sobre suas comunidades, levando informações que ultrapassam as barreiras transnacionais. 
Palavras-chave: migrações transnacionais; comunicação cidadã; internet.

\begin{abstract}
Media practices of Latin American (im)migrants worldwide: towards a promotion of citizenship and sociability - The book is an investigation outcome developed from 2007 to 2009 by the research group Mídia, Cultura e Cidadania, linked to the Post-graduation program in Communication Sciences, at UNISINOS. It aims to map the media production practices of persons involved or not with Latin American immigrant associations, in addition to independent migration organizations. Such practices are related to information spaces made available by the internet, like blogs, websites, and social networks, as well as printed media like newspapers and magazines, which are considered by the author as "multi-territorial media spaces". Through the latter, the immigrants are able to establish connections with their net of sociabilities, and promote information on their communities, broadcasting knowledge that overcomes transnational barriers.
\end{abstract}

Keywords: transnational migration; citizen communication; social networks.

A cidadania e a mobilização social podem ser exercidas por meio das tecnologias da comunicação presentes na contemporaneidade, por indivíduos que estão em mobilidade nos fluxos migratórios transnacionais. Este é um dos objetos de estudo do livro "Latinoamericanos em diáspora: usos de mídias e cidadania das migrações transnacionais", de autoria da comunicóloga Denise Maria Cogo.

O corpus da pesquisa central reuniu noventa mídias, entre as quais destacamse meios impressos e digitais, produzidas por imigrantes e/ou associações voltadas para o monitoramento e receptividade da diáspora latino-americana pelo mundo. Somam-se, ainda, dez entrevistas realizadas no Brasil, em Porto Alegre e em São Paulo, e, em âmbito internacional, Buenos Aires, Barcelona e Lisboa. Entre os objetivos, a busca da compreensão em como se deu a correlação entre as matrizes culturais de ordem nacional e supranacional, envolvendo o Mercosul, a América Latina e a União Europeia, e a construção da noticiabilidade dos fluxos migratórios relativa aos latino-americanos, visando sua integração e manutenção de suas redes sociais. A criação, manutenção e divulgação dessas práticas midiáticas promovem, por conseguinte, a cidadania comunicativa dos migrantes transnacionais, sobretudo aqueles em mobilidade no espaço ibero-americano.

Com cinco capítulos, além do prólogo e demais adicionais, Cogo detalha que o espaço midiático assume uma reconfiguração espaço-temporal nas interações humanas. A mobilidade presente de forma constante na vida de alguns indivíduos é impactada pela mídia, que também influencia diversos setores sociais, movimentados pela informação. Nesse sentido, a sociedade se configura em um ambiente digital, criando redes de informação e sociabilidades.

Um dos conceitos destacados está o de comunicação cidadã. O termo foi utilizado entre as décadas de 1970 e 1990 como “... 'questão comunicacional' na agenda de lutas da sociedade civil marcada especificamente pela preocupação com a democratização dos processos comunicacionais e midiáticos no contexto latino-americano" 
(COGO, 2012, p. 26). Seria considerada a principal condição para que fosse possível alcançar a equidade social aos que dela fizessem uso. Em uma perspectiva mais recente, o conceito volta a ser utilizado diante da manifestação de meios considerados cidadãos, notadamente a internet, por meio dos quais os usuários podem reportar acontecimentos ocorridos em seu contexto social, sem depender exclusivamente dos meios de comunicação tradicionais.

Assim, os movimentos migratórios fazem uso desses canais de informação e divulgação autônoma de conteúdo como "espaços comunicacionais transnacionais" (COGO, 2012, p. 29). Por meio deles, os migrantes promoveriam o que autores como Martín-Barbero, Maria Cristina Mata e a própria Denise Cogo denominam "cidadania comunicativa" (COGO, 2012, p. 30), com a "... participação da sociedade na propriedade, gestão, produção e distribuição dos recursos comunicacionais". No caso dos imigrantes, essa cidadania comunicativa possibilitaria a troca de experiências entre seus pares e demais indivíduos em trânsito para suas localidades, visando o fomento de informação sobre temas de ordem econômica, política, social, cultural e global sobre suas vivências.

Uma vez que são representados comumente em imagens midiáticas relativas aos conflitos e criminalidade, como as pesquisas empreendidas pelo grupo liderado por Cogo apontaram, os migrantes transnacionais conseguem, por meio de seus canais de informação, promover suas próprias representações, de forma que possam ser integrados e reconhecidos do modo como desejam ser vistos.

As redes sociais migratórias consistem, portanto, nas relações negociadas pelos indivíduos migrantes, de forma individual ou coletiva, com seus familiares, amigos e demais conhecidos de seu país de nascimento ou origem, por meio dos canais que estabelecem com esses interlocutores. Questões culturais são valorizadas nesses espaços, ao passo que são pensadas formas de inserção desses migrantes nos países de migração por onde circulam. Dessa forma, a mídia opera de modo transnacional para fortalecer a diáspora.

Aos que pesquisam sobre migrações, nacionais ou transnacionais, e sua relação com a mídia, independente do suporte midiático analisado, a obra é leitura recomendada, promovendo reflexão teórica e apoio metodológico com base em estudos da Comunicação, Sociologia e Antropologia.

Samira Moratti Frazão é doutoranda no Programa de Pós-Graduação em História da UDESC (PPGH/FAED/ UDESC). É mestre pelo Programa de Pós-Graduação em Jornalismo (POSJOR/UFSC). É pesquisadora do Grupo de Relações de Gênero e Família (LABGEF/UDESC), do Grupo Interinstitucional de Pesquisa em Telejornalismo (GIPTele/ UFSC) e do Observatório das Migrações de Santa Catarina. 